Check for updates

Cite this: RSC Adv., 2018, 8, 38506

Received 20th July 2018

Accepted 5th November 2018

DOI: $10.1039 / c 8 r a 06145 a$

rsc.li/rsc-advances

\section{A combination of experiment and theoretical methods to study the novel and low-cost corrosion inhibitor 1-hydroxy-7-azabenzotriazole for mild steel in $1 \mathrm{M}$ sulfuric acid}

\begin{abstract}
Lanzhou Gao, (D)* Shini Peng, Zhili Gong and Jie Chen
1-Hydroxy-7-azabenzotriazole (HOAT) was explored via experimental and theoretical computation methods as a corrosion inhibitor for mild steel in $1 \mathrm{M}$ sulfuric acid. These data indicate that HOAT has good ability to suppress corrosion of the mild steel, with ideal agreement with between experimental and computational results. Besides, the electrochemical experiments show that HOAT is a mixed-type corrosion inhibitor for mild steel in $1 \mathrm{M} \mathrm{H}_{2} \mathrm{SO}_{4}$. Furthermore, HOAT adsorption on the surface of steel conforms to the Langmuir isotherm model. Finally, computational simulation was executed to deeply investigate the mechanism to HOAT inhibition corrosion of steel.
\end{abstract}

\section{Introduction}

Mild steel has a wide range of applications in production and life because of its excellent properties. ${ }^{1-5}$ These include the production of various building components, containers, tanks, furnaces and agricultural machinery, in addition to various heat exchange equipment, heat transfer equipment and cooling equipment, etc. However, thermal equipment such as boilers and heat exchangers gradually form various types of dirt during use, and the poor thermal conductivity of this dirt causes the local temperature of the furnace tubes to rise, which reduces the strength of steel materials and often causes tube explosion accidents as well as affecting the boiler operation. Therefore, pickling plays a very important role in boiler operation of a power plant to remove these dirt and oxidation products.

Sulfuric acid is the most commonly used pickling solution. It can effectively remove metal surface dirt and oxidation products. ${ }^{6}$ However, sulfuric acid has certain corrosion effects on the substrate of metal equipment. ${ }^{7}$ At the same time, the hydrogen released will diffuse into the interior of the metal, causing hydrogen embrittlement in the washed equipment. In addition, a large amount of acid gas that is precipitated will deteriorate working conditions. Therefore, corrosion inhibitors should be added during pickling to inhibit the corrosion of metals in acidic media, reducing the amount of acid used, improving the pickling effect, and extending the service life of thermal equipment.

The majority of pickling corrosion inhibitors are organic compounds containing oxygen $(\mathrm{O})$, nitrogen $(\mathrm{N})$, sulfur $(\mathrm{S})$,

School of Urban Construction and Environmental Engineering, Chongqing University, Chongqing, China. E-mail: zhougl8209@163.com phosphorus (P), etc. ${ }^{8-15}$ Such as amines, thioureas, aldehydes and ketones phosphorus compounds. Its mechanism of action differs from the fact that inorganic corrosion inhibitors with no surface activity undergo chemical reactions on the metal surface, relying on molecular adsorption to form molecularly oriented protective films on the surface of metal to prevent corrosion of the metal by corrosive media. On the one hand, oxygen, nitrogen, sulfur, phosphorus and other elements contain lone pair electrons, and they all exist as polar groups in organic compounds. On the other hand, transition metals such as iron and copper can be used as electron acceptors when they are not filled with d electron orbitals. These elements coordinate with metal elements to form a strong chemical adsorption layer. In addition, double bonds, triple bonds, and benzene rings can also be chemically adsorbed on metal surfaces by the action of $\pi$ bonds.

In this work, we studied for the first time the corrosion inhibition performance of 1-hydroxy-7-azabenzotriazole (HOAT), an organic compound of triazole, in low-carbon steel in sulfuric acid solution. It has not been reported in other literatures.

\section{Experimental}

\subsection{Material}

The $1 \mathrm{M}$ sulfuric acid corrosion solution was prepared with analytically pure concentrated sulfuric acid and ultrapure water. HOAT was added to $1 \mathrm{M}$ sulfuric acid solution to prepare $0.5,1$, 2, 5, and $10 \mathrm{mM}$ solution. The HOAT structure was shown in Fig. 1 and HOAT was purchased at Adamas Reagent Co., Ltd. The purity of HOAT is greater than $99.9 \%$. The chemical composition (in wt\%) of mild steel as follow: $\mathrm{C}$ is $0.1 \%$, $\mathrm{Si}$ is 


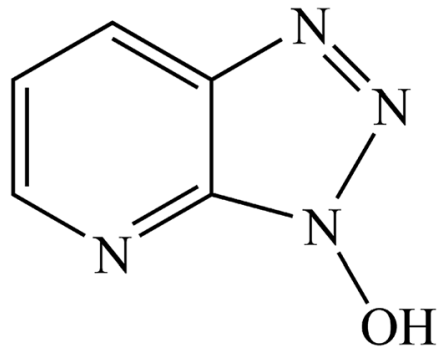

Fig. 1 Molecular structural formula of the 1-hydroxy-7azabenzotriazole.

$0.035 \%, \mathrm{Mn}$ is $0.4 \%, \mathrm{Cr}$ is $0.3 \%, \mathrm{Ni}$ is $0.3 \%$ and the rest is iron. The mild steel working electrode was cut into $1 \times 1 \times 1 \mathrm{~cm}^{3}$ squares and then mounted in epoxy to leave a $1 \times 1 \mathrm{~cm}^{2}$ work surface exposed to the test system. The mild steel electrode was sanded on sandpaper $(400,800,1200$, and 2000 mesh) prior to electrochemical measurement experiments. Then it was washed with distilled water, absolute ethanol and acetone solution, and finally the electrode surface was dried at room temperature.

\subsection{Weight loss experiment}

Weight-loss test samples (mild steel) were cut into $5.0 \times 2.5 \times$ $0.5 \mathrm{~cm}^{3}$ cuboids. These samples were hung to HOAT in different concentrations $(0.5,1,2,5$, and $10 \mathrm{mM})$ solution and $1 \mathrm{M} \mathrm{H}_{2} \mathrm{SO}_{4}$ solution in triplicate for 4 hours at different temperatures (298 $\mathrm{K}, 308 \mathrm{~K}, 318 \mathrm{~K}$, and $328 \mathrm{~K}$ ), respectively. These mild steel cuboids were carefully washed via banister brush with distilled water, absolute ethanol and acetone. Finally, these mild steel cuboids were dried and weighed.

\subsection{Electrochemical tests}

All electrochemical tests were executed at $298 \mathrm{~K}$ via the chi760e electrochemical workstation, a product of Shanghai Chenhua Co., Ltd, using a three-electrode system. Mild steel acts as a working electrode $\left(1 \times 1 \mathrm{~cm}^{2}\right)$, saturated calomel electrode with Luggin capillary as a reference electrode, and a platinum electrode $\left(1 \times 1 \mathrm{~cm}^{2}\right)$ as a counter electrode. Firstly, Mild steel electrode was dipped in the test solution for thirty minutes to measure its open circuit potential (OCP) and obtain stable state. Electrochemical impedance spectroscopy (EIS) was carried out under the $E_{\mathrm{OCP}}$ with the frequency range from $10^{5} \mathrm{~Hz}$ to $10^{-2}$ Hz. Corresponding EIS parameters are fitted using Zsimpwin software. Tafel curves were tested with in the potential range of $-0.25 \mathrm{~V}$ to $+0.25 \mathrm{~V} v s$. $E_{\mathrm{OCP}}$ in the scan rate of $0.5 \mathrm{mV} \mathrm{s}^{-1} \cdot{ }^{16}$ Electrochemical tests at each concentration were repeated three times to get a perfect same result.

\subsection{Surface analysis}

Mild steel were cut into $0.5 \times 0.5 \times 0.5 \mathrm{~cm}^{3}$ cuboids. After sanding carefully, the steel samples soaked at $298 \mathrm{~K}$ in $1 \mathrm{M}$ $\mathrm{H}_{2} \mathrm{SO}_{4}$ solutions in the absence and presence HOAT $(10 \mathrm{mM})$ for 2 hours. The corrosion product of the tested steel surface was fully rinsed via distilled water and a soft brush. After that, the steel surface was observed using SEM (JEOL-JSM-7800F), under high vacuum condition. Pretreatment of the steel sample surface in the same manner as the test SEM. The 3D images and the average roughness of the steel surfaces were tested using AFM (MFP-3D-BIO), using tapping mode.

\subsection{Calculation details}

Quantum chemistry of HOAT molecule was calculated via Gaussian 03W. Based on the density functional theory, the basis set is 6-311++G (d, p), the job type is Opt + Freq, and the B3LYP as a function quantifies HOAT molecule. To more closely simulate the real state of HOAT in $1 \mathrm{M}$ sulfuric acid. We calculated the morphology of different HOAT heteroatoms after protonation, and further compared their optimized energies. The lowest energy, the most stable protonated state of $\mathrm{HOATH}^{+}$ is used for the subsequent dynamics simulation.

$\mathrm{HOATH}^{+}$adsorption on the mild steel was studied using Dynamic simulations with forcite module in Material Studio 8.0. The model of Fe (110) surface was chose as simulated substrate due to low Miller index steel surface. $\mathrm{HOATH}^{+}$and three hundred $\mathrm{H}_{2} \mathrm{O}$ molecules adsorption on the $\mathrm{Fe}$ (110) surface were assumed in the simulation $3 \mathrm{D}$ box $(2.1 \times 2.2 \times 4.1$ $\mathrm{nm}^{3}$ ) with COMPASS force field. The calculation task is dynamics, fine as the optimization type of quality. Energy is $1 \times$ $10^{-4} \mathrm{kcal} \mathrm{mol}^{-1}$. Force is $0.005 \mathrm{kcal} \mathrm{mol}^{-1} \AA^{-1}$. Displacement is $5 \times 10^{-5}$ A. Max iterations is 500. Electrostatic and van der Waals are all set to Ewald. Charges is Forcefield assigned. The four layers of Fe atoms restricted their position and the $298 \mathrm{~K}$ as simulated temperature, NVT as the specification set, $1 \mathrm{fs}$ as the time step, and $300 \mathrm{ps}$ as the simulation time.

\section{Results and discussion}

\subsection{Weight loss experiment}

Weight loss tests were carried out in diverse temperatures (298 $\mathrm{K}, 308 \mathrm{~K}, 318 \mathrm{~K}$, and $328 \mathrm{~K}$ ) in $1 \mathrm{M} \mathrm{H}_{2} \mathrm{SO}_{4}$ without and with different concentrations HOAT. The weight loss data were presented in the Table 1 . Mild steel corrosion rate $(\nu)$, inhibition efficiency $(\eta)$ and surface coverage $(\theta)$ are calculated, respectively, as followings: ${ }^{17-19}$

$$
\begin{gathered}
\nu=\frac{W}{S t} \\
\eta=\frac{\nu_{0}-\nu}{\nu_{0}} \times 100 \\
\theta=\frac{\nu_{0}-\nu}{\nu_{0}}
\end{gathered}
$$

where $W$ represents the difference value between the steel mass before and after weight loss test. $S$ represents the steel surface area. $t$ represents the time of the researched samples soaked in the corrosion solution, $\nu_{0}$ is the mild steel corrosion rate without HOAT and $\nu$ is the mild steel corrosion rate with different concentrations of HOAT.

As shown in Table 1, it can be find that the values of $v$ of researched steel increases sharply with $1 \mathrm{~mol}^{-1} \mathrm{H}_{2} \mathrm{SO}_{4}$ without HOAT with the increase of temperatures. Furthermore, 
Table 1 The weight loss experiment data to steel in $1 \mathrm{~mol} \mathrm{~L}^{-1} \mathrm{H}_{2} \mathrm{SO}_{4}$ with and without diverse concentrations of HOAT for four hours at diverse temperatures

\begin{tabular}{llrll}
\hline$T(\mathrm{~K})$ & $C(\mathrm{mM})$ & $V\left(\mathrm{~g} \mathrm{~m}^{-2} \mathrm{~h}^{-1}\right)$ & $\eta(\%)$ & $\theta$ \\
\hline \multirow{2}{*}{298} & Blank & 18.71 & - & - \\
& 0.5 & 2.39 & 87.2 & 0.872 \\
& 1 & 2.15 & 88.5 & 0.885 \\
& 2 & 1.81 & 90.3 & 0.903 \\
& 5 & 1.36 & 92.7 & 0.927 \\
308 & 10 & 0.95 & 94.9 & 0.949 \\
& Blank & 28.92 & - & - \\
& 0.5 & 6.22 & 78.5 & 0.785 \\
& 1 & 5.69 & 80.3 & 0.803 \\
& 2 & 5.17 & 82.1 & 0.821 \\
& 5 & 3.99 & 86.2 & 0.862 \\
& 10 & 2.34 & 91.9 & 0.919 \\
& Blank & 40.86 & - & - \\
& 0.5 & 12.13 & 70.3 & 0.703 \\
& 1 & 10.34 & 74.7 & 0.747 \\
& 2 & 9.35 & 77.1 & 0.771 \\
& 5 & 7.23 & 82.3 & 0.823 \\
328 & 10 & 3.80 & 90.7 & 0.907 \\
& Blank & 62.13 & - & - \\
& 0.5 & 26.84 & 56.8 & 0.568 \\
& 1 & 21.06 & 66.1 & 0.661 \\
& 2 & 16.28 & 73.8 & 0.738 \\
& 5 & 10.87 & 82.5 & 0.825 \\
& 10 & 7.02 & 88.7 & 0.887 \\
& & & & \\
& & & & \\
& & & &
\end{tabular}

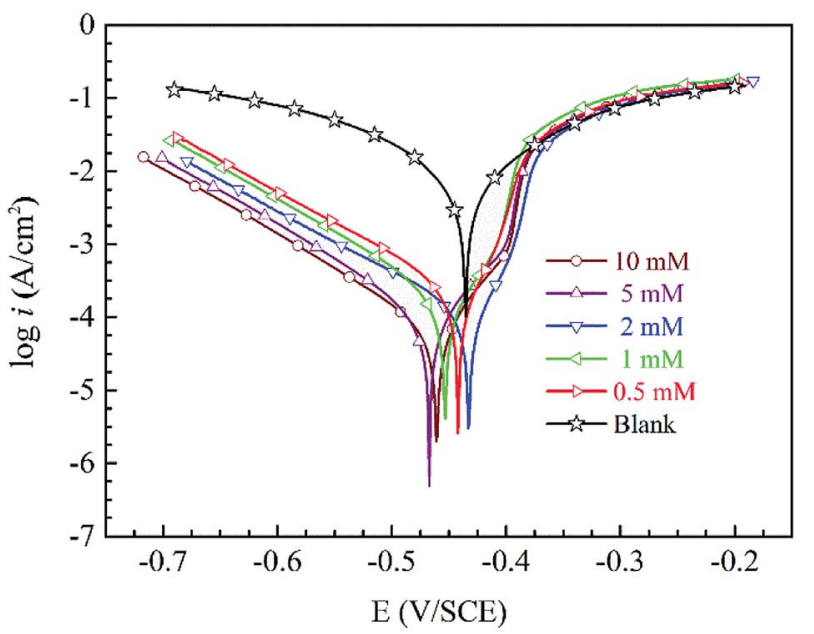

Fig. 2 Tafel curves for mild steel at $298 \mathrm{~K}$ in $1 \mathrm{M} \mathrm{H}_{2} \mathrm{SO}_{4}$ without and with different concentrations of HOAT. it can get conclusion that as the concentrations of HOAT increases, the $v$ decreases and the $\eta$ increases significantly, indicating that increase of HOAT concentrations are favorable to increase the adsorption amount of mild steel surface inhibitors. The $\eta$ of HOAT is up to $94.9 \%$ with the HOAT concentration reaching $10 \mathrm{mM}$ at $298 \mathrm{~K}$, which shows that HOAT can effectively adsorb on steel surface. In addition, the $\eta$ shows a downward trend with the augment of temperatures, which indicates that the augment of the temperature causes the thermal motion of the inhibitor molecules to increase, which is unfavorable for the HOAT molecules adsorption on the steel surface. Whereas, when the concentrations ( $5 \mathrm{mM}$ and $10 \mathrm{mM}$ ) of HOAT are high, excellent performance of steel corrosion inhibition in $1 \mathrm{~mol} \mathrm{~L}^{-1} \mathrm{H}_{2} \mathrm{SO}_{4}$ can still be exhibited at high temperature.

\subsection{Tafel curves}

Tafel curves of steel at $298 \mathrm{~K}$ in $1 \mathrm{~mol} \mathrm{~L}^{-1} \mathrm{H}_{2} \mathrm{SO}_{4}$ without and with diverse concentrations of the HOAT are displayed in Fig. 2.

To further understand the inhibition mechanism of HOAT to mild steel in the $1 \mathrm{~mol} \mathrm{~L}^{-1} \mathrm{H}_{2} \mathrm{SO}_{4}$, relevant parameters are shown in Table 2. Using extrapolation to obtain the corrosion voltage $\left(E_{\text {corr }}\right)$ and corrosion current density $\left(I_{\text {corr }}\right)$. The important electrochemical parameters are showed in Table 2. The $\eta$ is calculated via eqn (4) as following: $:^{20-26}$

$$
\eta=\frac{I_{\text {corr }, 0}-I_{\text {corr }}}{I_{\text {corr }, 0}} \times 100
$$

where $I_{\text {corr }}$ and $I_{\text {corr,o }}$ are current densities with and without HOAT in the $1 \mathrm{M} \mathrm{H}_{2} \mathrm{SO}_{4}$, respectively.

In Fig. 2, cathodic and anodic polarization curves transfer obviously to lower electric current with adding of HOAT, which means the accretion of HOAT decreases anodic steel dissolution and prevents reduction of the hydrogen ions. In addition, the cathode current density decline trend is more obvious than the anode, which shows that HOAT adsorption on mild steel effectively inhibits the evolution of hydrogen at the cathode. By observing the anodic polarization curve, it can be found that when the polarization potential is high, HOAT shows a significant desorption phenomenon on the steel surface.

As showed in Table 2, the $\eta$ augments markedly with the increase of researched inhibitor concentrations. Moreover, corrosion potentials move in the cathode direction with increasing HOAT concentrations. The maximum subtractive shift value is $32 \mathrm{mV}$ and less than $85 \mathrm{mV} .{ }^{27}$ Therefore, HOAT is a mixed-type corrosion inhibition behavior for steel in sulfuric

Table 2 Parameters of electrochemistry for mild steel at $298 \mathrm{~K}$ in $1 \mathrm{M} \mathrm{H}_{2} \mathrm{SO}_{4}$ without and with diverse concentrations of HOAT

\begin{tabular}{lllll}
\hline$C\left(\mathrm{mM} \mathrm{L}^{-1}\right)$ & $E_{\text {corr }}(\mathrm{mV} / \mathrm{SCE})$ & $I_{\text {corr }}\left(\mathrm{mA} \mathrm{cm}^{-2}\right)$ & $\left.\beta_{\mathrm{c}}(\mathrm{mV} \mathrm{dec})^{-1}\right)$ & $\beta_{\mathrm{a}}\left(\mathrm{mV} \mathrm{dec}^{-1}\right)$ \\
\hline Blank HOAT & -435 & 2.48 & -39.84 & 42.1 \\
0.5 & -442 & 0.26 & -120.04 & 38.48 \\
1 & -453 & 0.23 & -109.66 & 37.55 \\
2 & -433 & 0.15 & -126.39 & 38.59 \\
5 & -467 & 0.09 & -101.27 & 44.51 \\
10 & -461 & 0.08 & -104.01 & 39.26
\end{tabular}



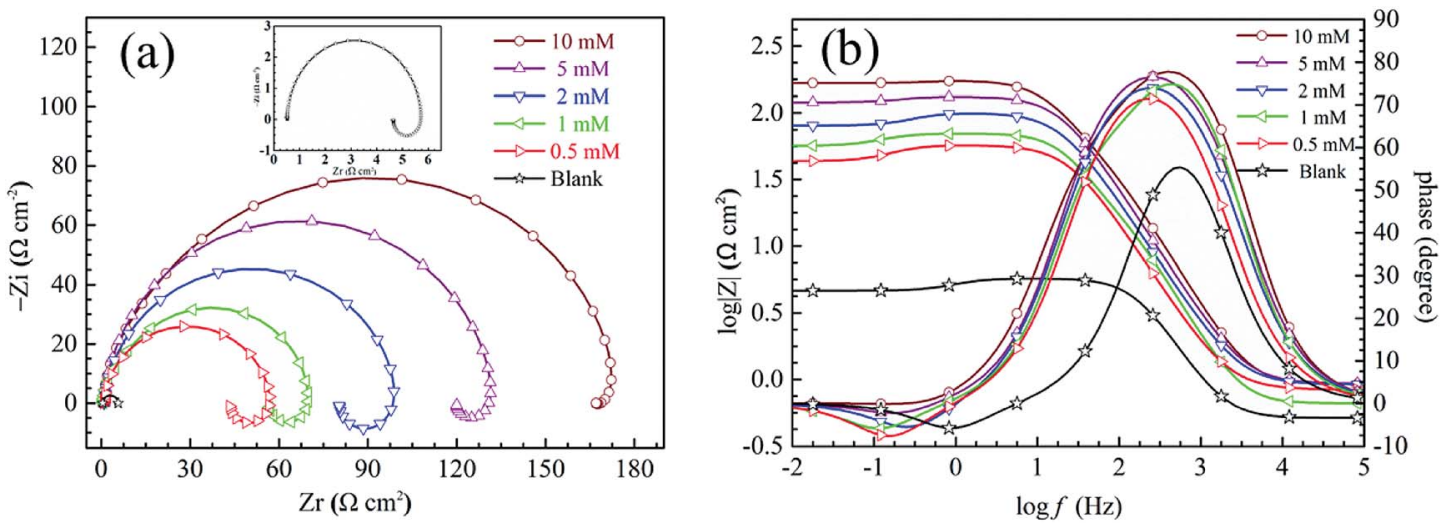

Fig. 3 EIS plots of the mild steel at $298 \mathrm{~K}$ in $1 \mathrm{M} \mathrm{H}_{2} \mathrm{SO}_{4}$ solution without and with diverse concentrations of HOAT: (a) Nyquist and (b) Bode plots.

acid. We can find that the values of $\beta_{\mathrm{c}}$ and $\beta_{\mathrm{a}}$ changed with different concentrations HOAT, indicating that the HOAT can control the cathode and anode reactions. Furthermore, the $\eta$ acquired from Tafel curves have an ideal accord with the weight loss tests.

\subsection{EIS measurements}

The plots of steel Nyquist (a) and Bode (b) in $1 \mathrm{M}$ sulfuric acid at $298 \mathrm{~K}$ without and with diverse concentrations of HOAT are presented in Fig. 3. It can be found that the Nyquist plots are defective capacitive loops, which indicate that steel corrosion are dominated by process of charge shift in the test solution. ${ }^{28,29}$ The capacitive loop shows non-ideal semicircle in test solution due to the roughness and inhomogeneity surface of mild steel electrode.$^{30}$ From Fig. 3(a), all of the Nyquist plots are constituted of capacitive loop and inductive loop corresponding to in the high and low frequency area, respectively. As the HOAT concentrations increase, the radius of the capacitive loop increases significantly, while the inductive loop gradually

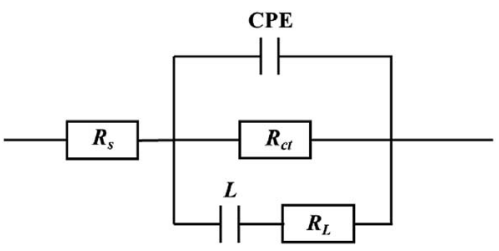

decreases in the low frequency area. This phenomenon is called impedance spectrum "degradation", which shows that HOAT molecules effectively inhibit steel corrosion in $1 \mathrm{M} \mathrm{H}_{2} \mathrm{SO}_{4}$.

The capacitive loop of high frequency ascribe to double layer capacitance and charge shift resistance. As the HOAT concentration increases, the radius of the capacitive loop increases significantly, indicating that HOAT molecules adsorption on the surface of steel greatly increases charge shift resistance. ${ }^{31}$ The inductive loop of low frequency ascribe to adsorption species as $\mathrm{SO}_{4}{ }^{2-}$ and $\mathrm{H}^{+}$on the mild steel surface or to the passivated surface re-dissolution of mild steel. ${ }^{11}$

As shown the Bode plot in Fig. 3(b), the values of impedance modulus and phase angle significantly increase with the HOAT concentrations increases. The value of impedance modulus increases two orders of magnitude and phase angle increased to $80^{\circ}$ with the HOAT reaches optimum concentration $(10 \mathrm{mM})$, which indicates that the adsorption of HOAT effectively inhibits the steel corrosion in $1 \mathrm{~mol} \mathrm{~L}^{-1} \mathrm{H}_{2} \mathrm{SO}_{4}{ }^{30}$

In order to obtain the impedance spectrum parameters, corresponding equivalent circuit is executed to fit the data of impedance spectrum in Fig. $4 . R_{\mathrm{S}}$ stands for the solution resistance, $R_{\mathrm{ct}}$ represents the charge transfer resistance, $L$ and $R_{\mathrm{L}}$ are inductive and inductive resistance, respectively. CPE stands for constant phase element. The impedance of the CPE is obtained via formula (5) as following: ${ }^{32-34}$

$$
Z_{\mathrm{CPE}}=\frac{1}{Y_{0}(\mathrm{j} \omega)^{n}}
$$

Fig. 4 The best equivalent circuit model to use for fitting.

Table 3 Impedance parameters for mild steel at $298 \mathrm{~K}$ in $1 \mathrm{M} \mathrm{H}_{2} \mathrm{SO}_{4}$ with and without diverse concentrations of the HOAT

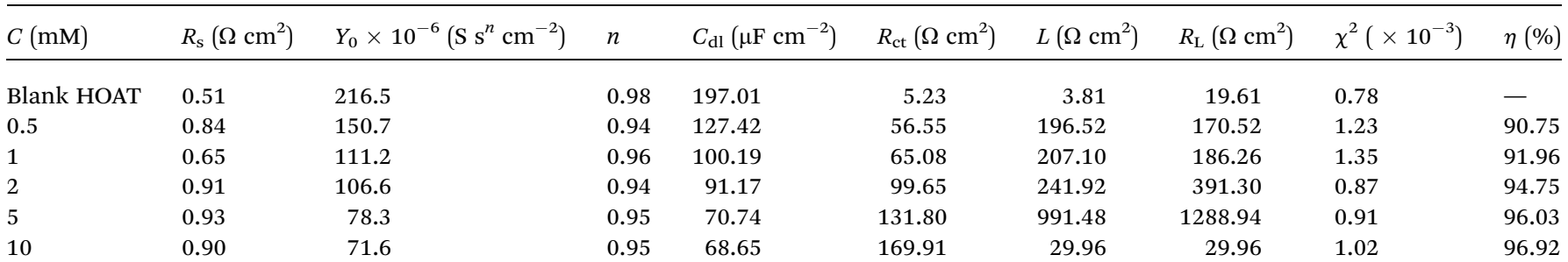



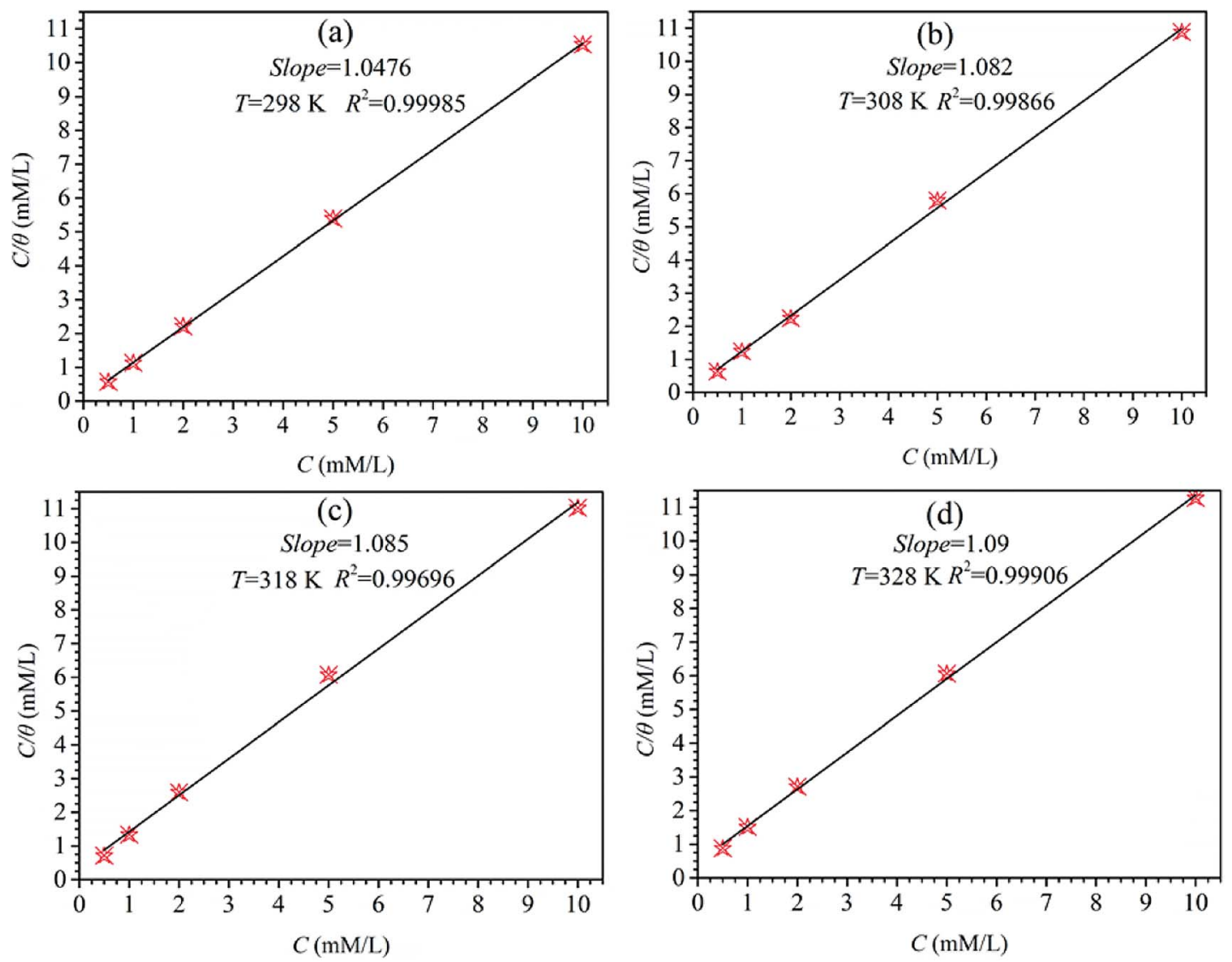

Fig. 5 The plots of Langmuir isotherm for mild steel in $1 \mathrm{M} \mathrm{H}_{2} \mathrm{SO}_{4}$ including different concentrations of HOAT at diverse temperatures (298 $\mathrm{K}$, $308 \mathrm{~K}, 318 \mathrm{~K}$ and $328 \mathrm{~K})$.

where $Y_{0}$ represents the CPE constant, $\mathrm{j}$ represents the imaginary root and $\omega$ represents the angular frequency. $n$ represents the deviation parameter. Double layer capacitance $\left(C_{\mathrm{dl}}\right)$ is used to replace CPE because it can more accurately fit the impedance values. The $C_{\mathrm{dl}}$ is calculated as follow: ${ }^{35,36}$

$$
C_{\mathrm{dl}}=\left(Y_{0} R_{\mathrm{ct}}^{1-n) 1 / n}\right.
$$

The vital impedance parameters are presented in Table 3 . The $\eta$ is obtained via formula (7) as following: $:^{37,38}$

$$
\eta=\frac{R_{\mathrm{ct}}-R_{\mathrm{ct}, 0}}{R_{\mathrm{ct}}} \times 100 \%
$$

where $R_{\mathrm{ct}, 0}$ and $R_{\mathrm{ct}}$ stand for the charge transfer resistances in the absence and presence of diverse concentrations HOAT, respectively.

Table 3 indicates that values of $R_{\mathrm{ct}}$ augment, accordingly, the $\eta$ values augment, which reveals that HOAT can availably

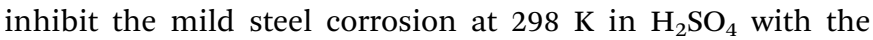
increase of concentrations, whereas, the values of $C_{\mathrm{dl}}$ reduce with the augment of HOAT concentrations. This phenomenon can be explained using the Helmholtz model as follow: ${ }^{39}$

$$
C_{\mathrm{dl}}=\frac{\varepsilon^{0} \varepsilon}{d} S
$$

where $\varepsilon^{0}$ stands for the air dielectric constant, $\varepsilon$ stands for local dielectric constant. $S$ is surface area of work electrode. $d$ stands for the thickness of double layer. On the one hand, the dielectric

Table 4 The thermodynamic parameters at diverse temperatures for mild steel in $1 \mathrm{M} \mathrm{H}_{2} \mathrm{SO}_{4}$ solution including different concentrations of HOAT

\begin{tabular}{lclll}
\hline Temperature $(\mathrm{K})$ & $K_{\text {ad }}\left(10^{3} \mathrm{~L} \mathrm{~mol}^{-1}\right)$ & $\Delta G_{\text {ads }}^{0}\left(\mathrm{~kJ} \mathrm{~mol}^{-1}\right)$ & $\Delta H_{\text {ads }}^{0}\left(\mathrm{~kJ} \mathrm{~mol}^{-1}\right)$ & $\Delta S_{\text {ads }}^{0}\left(\mathrm{~J} \mathrm{~K} \mathrm{~mol}^{-1}\right)$ \\
\hline 298 & 10.71 & -32.94 & -25.69 & -24.50 \\
303 & 6.33 & -32.69 & -23.93 \\
308 & 2.99 & -31.78 & -23.57 \\
313 & 2.21 & -31.95 & -26.39
\end{tabular}


constant value of HOAT is lower than that of water molecules. On the other hand, HOAT has a larger molecular volume than water. Therefore, the local dielectric constant decreases and the $d$ value of the double layer capacitance augments with HOAT replaces the water molecules on the surface of work electrode, resulting in a decrease in the $C_{\mathrm{dl}}$ values. ${ }^{40}$ In addition, the values of deviation index $n$ are very close to 1 , which manifests the behaves of steel interface nearly capacitive.

\subsection{Adsorption isotherm and thermodynamic research}

In general, corrosion inhibitors restrain metal corrosion via adsorption on the surface of metal, whereas the adsorption isotherm help understand vital information about corrosion inhibitors adsorption on surface of metal. Some important adsorption isotherms, containing Temkin, Frumkin, FloryHuggins, Langmuir, El-Awady and so on, were used to fit weight loss experimental data. These results indicate that Langmuir adsorption isotherm shows a good linear relationship with weight loss test data. The Langmuir adsorption isotherm described as follow: ${ }^{41-44}$

$$
\frac{C}{\theta}=\frac{1}{K_{\mathrm{ads}}}+C
$$

where $C$ is HOAT concentration, $\theta$ is the coverage of surface $(\eta)$ 100 ), which gained in Table 1 by weight loss test. $K_{\text {ads }}$ is the equilibrium constant of adsorption.

The $C v s$. $C / \theta$ obtain straight lines with $R^{2}$ and the slope near 1 at different temperatures as shown in Fig. 5 . The slope values at different temperatures is very close to 1 , indicating that the adsorption of HOAT in steel is consistent with Langmuir adsorption isotherm. The standard adsorption free energy $\left(\Delta G_{\mathrm{ads}}^{0}\right),{ }^{45-47}$ enthalpy, and entropy are obtained by the following equations: ${ }^{32}$

$$
\begin{gathered}
K_{\mathrm{ads}}=\frac{1}{55.5} \exp \left(-\frac{\Delta G_{\mathrm{ads}}^{0}}{R T}\right) \\
\ln K_{\mathrm{ads}}=-\frac{\Delta H_{\mathrm{ads}}^{0}}{R T}+\text { constant } \\
\Delta G_{\mathrm{ads}}^{0}=\Delta H_{\mathrm{ads}}^{0}-T \Delta S_{\mathrm{ads}}^{0}
\end{gathered}
$$

where the 55.5 is the molar concentration of $\mathrm{H}_{2} \mathrm{O} . R$ is the universal gas constant. $T$ is the absolute temperature.

Via the eqn (11), $\ln K_{\text {ads }} v s$. $1 / T$ to obtain a straight line is appeared in Fig. 6. The thermodynamic parameters, such as $\Delta H_{\text {ads }}^{0}, \Delta S_{\text {ads }}^{0}, \Delta G_{\text {ads }}^{0}$ and $K_{\text {ads }}$, are presented in Table 4 . In generally, the large value of $K_{\text {ads }}$ and the small value of $\Delta G_{\text {ads }}^{0}$ indicate that the HOAT can compactly adsorb on the steel surface, effectively restrain mild steel corrosion. As shown in Table 4 , it can be found that the $K_{\text {ads }}$ values decreases and the $\Delta G_{\text {ads }}^{0}$ values increases with temperature augment, which means that decreases of corrosion inhibition ability of HOAT for steel in $\mathrm{H}_{2} \mathrm{SO}_{4}$ with increasing temperatures. This phenomenon is attributed to the fact that thermal excursions between molecules with increasing temperature are not conducive to the HOAT adsorption on surface of steel. In

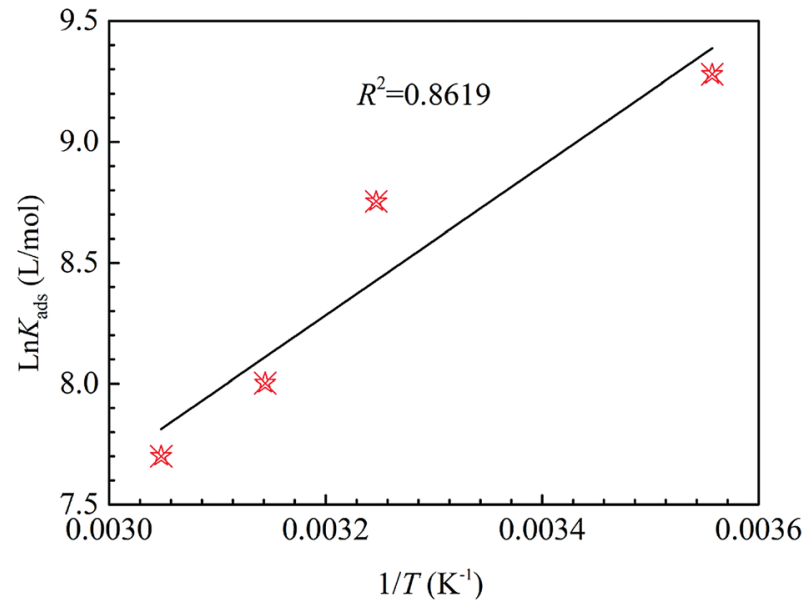

Fig. 6 The relation between $\ln K_{\text {ads }}$ and $1 / T$ for mild steel at $1 \mathrm{M} \mathrm{H}_{2} \mathrm{SO}_{4}$ containing different concentrations of HOAT.

addition, the value of $\Delta G_{\text {ads }}^{0}$ is between -31 and $-33 \mathrm{~kJ} \mathrm{~mol}^{-1}$, so it can be considered that the HOAT adsorption on the surface of steel is mainly based on physical and chemical adsorption. ${ }^{48}$ In addition, $\Delta H_{\text {ads }}^{0}$ is $-25.69 \mathrm{~kJ} \mathrm{~mol}^{-1}$, which indicates that the HOAT adsorption on the surface of steel is an exothermic process. ${ }^{11} \Delta S_{\text {ads }}^{0}$ are approximately between -24 and $-26 \mathrm{~J} \mathrm{k}^{-1}$ $\mathrm{mol}^{-1}$, indicating HOAT lose its translation freedom when adsorption on the steel. ${ }^{32}$

\subsection{Corrosion kinetic analysis}

The different temperatures influence on the mild steel corrosion in $1 \mathrm{M} \mathrm{H}_{2} \mathrm{SO}_{4}$ in the absence and presence different concentrations of HOAT has been explored. The relevant kinetic parameters including activation energy $\left(E_{\mathrm{a}}\right)$, activation enthalpy $\left(\Delta H_{\mathrm{a}}\right)$, and activation entropy $\left(\Delta S_{\mathrm{a}}\right)$ for steel corrosion in the absence and present various concentrations of HOAT are acquired via Arrhenius (13) and transition state formulas (14) as followings: ${ }^{11,32}$

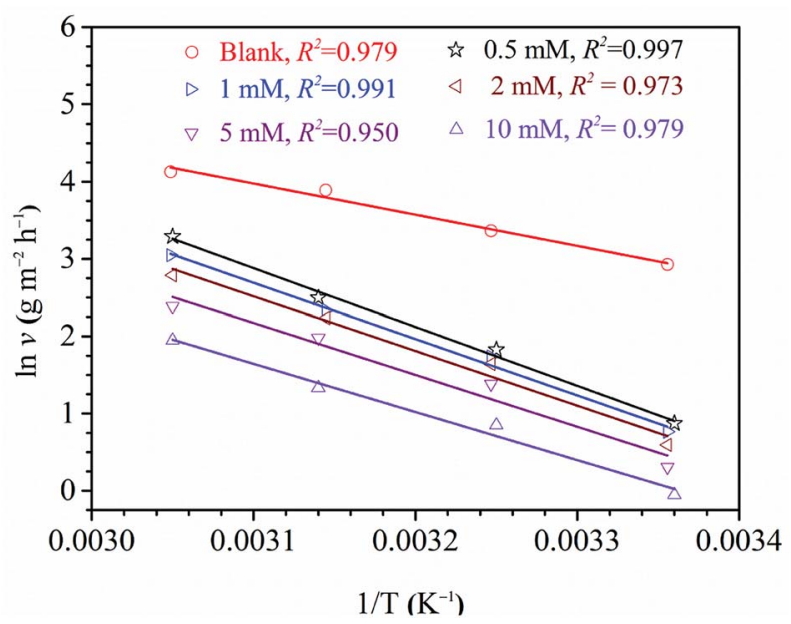

Fig. 7 The plots of Arrhenius for steel in $1 \mathrm{M} \mathrm{H}_{2} \mathrm{SO}_{4}$ without and with diverse concentrations of HOAT. 


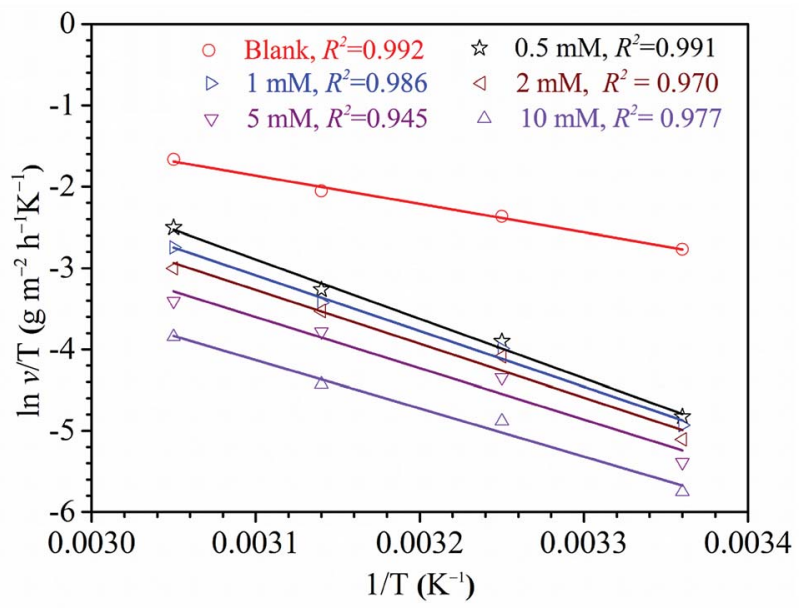

Fig. 8 The plots of transition state to steel in $1 \mathrm{M} \mathrm{H}_{2} \mathrm{SO}_{4}$ without and with diverse concentrations of HOAT.

$$
\ln \nu=\frac{E_{\mathrm{a}}}{R T}+\ln A
$$

$$
\ln \frac{\nu}{T}=\ln \frac{R}{N h}+\frac{\Delta S_{\mathrm{a}}}{R}-\frac{\Delta H_{\mathrm{a}}}{R T}
$$

where $R$ represents universal gas constant, $T$ represents thermodynamic temperature, $v$ represents corrosion rate, $A$ represents pre-exponential factor, $N$ represents Avogadro's number and $h$ represents Plank's constant. The $\ln v v s .1 / T$ presented in
Fig. 7. Moreover, the $\ln (v / T)$ vs. $1 / T$ presented in Fig. 8. The relevant kinetic parameters, $E_{\mathrm{a}}, \Delta H_{\mathrm{a}}$ and $\Delta S_{\mathrm{a}}$, are calculated via formulas (13) and (14).

As shown in Table 5, it is generally believed that the $E_{\mathrm{a}}$ and $\lambda$ values increase after adding HOAT, indicating that HOAT has physical adsorption on the steel surface at this stage. ${ }^{\mathbf{1 1 , 4 9 - 5 1}}$ When the HOAT concentration was $1 \mathrm{mM}$, it was clearly found that both the $E_{\mathrm{a}}$ and $\lambda$ values decreased, which was attributed to HOAT chemical adsorption on the steel surface. ${ }^{49}$ Therefore, HOAT adsorbs on the surface of steel by means of physical and chemical adsorption, which is highly accordant to the results obtained by thermodynamics. In addition, the values of $\Delta H_{\mathrm{a}}$ are positive, which indicates that the steel dissolution in sulfuric acid is an endothermic process. ${ }^{\mathbf{1 8 , 5 2}}$ Finally, the $\Delta S_{\text {a }}$ values are significantly larger than that of the blank solution in the presence of HOAT. This is due to the presence of competitive adsorption of HOAT molecules to replace the water molecules on the surface of mild steel to increase the degree of chaos. As the concentration of HOAT increases, the $\Delta S_{\mathrm{a}}$ values decreases, which is attributed to HOAT molecules forming a dense and ordered protective film on the steel surface, resulting decline in the degree of chaos of steel surface.

\subsection{Morphological analysis}

3.6.1. Scanning electron microscopic research. Fig. 9 presents the images of SEM about the specimens of researched steel after and before dip in $1 \mathrm{M}$ sulfuric acid for $2 \mathrm{~h}$ at $298 \mathrm{~K}$ in the presence and absence of the 10 mM HOAT. Fig. 9(a) shows the steel specimen soaked in $1 \mathrm{~mol} \mathrm{~L}^{-1}$ sulfuric acid for 2 hours. We can clearly see that the mild steel corrosion is very serious.

\begin{tabular}{|c|c|c|c|c|}
\hline $\begin{array}{l}\text { Concentrations } \\
(\mathrm{mM})\end{array}$ & $E_{\mathrm{a}}\left(\mathrm{kJ} \mathrm{mol}^{-1}\right)$ & $\Delta H_{\mathrm{a}}\left(\mathrm{kJ} \mathrm{mol}{ }^{-1}\right)$ & $\Delta S_{\mathrm{a}}\left(\mathrm{J} \mathrm{k}^{-1} \mathrm{~mol}^{-1}\right)$ & $\lambda$ \\
\hline Blank & 33.60 & 28.90 & -138.01 & $1.47 \times 10^{7}$ \\
\hline 1 & 60.59 & 56.96 & -61.52 & $9.58 \times 10^{10}$ \\
\hline 2 & 58.82 & 55.06 & -68.92 & $4.15 \times 10^{10}$ \\
\hline 5 & 55.83 & 52.38 & -79.98 & $9.63 \times 10^{9}$ \\
\hline
\end{tabular}

Table 5 Kinetic parameters in $1 \mathrm{~mol} \mathrm{~L}^{-1} \mathrm{H}_{2} \mathrm{SO}_{4}$ for steel with and without of diverse concentrations of HOAT
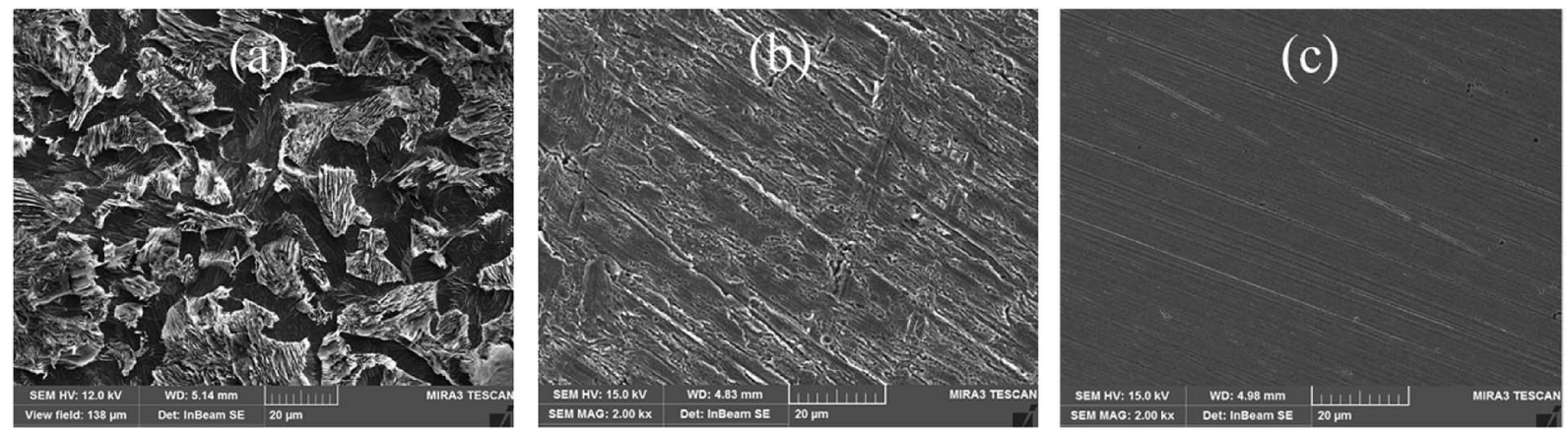

Fig. 9 The mild surface dipped in $1 \mathrm{M} \mathrm{H}_{2} \mathrm{SO}_{4}$ without HOAT (a) and with $10 \mathrm{mM} \mathrm{HOAT} \mathrm{(b)} \mathrm{and} \mathrm{freshly} \mathrm{burnished} \mathrm{steel} \mathrm{surface} \mathrm{(c)} \mathrm{of} \mathrm{SEM} \mathrm{at} 298 \mathrm{~K}$ for $2 \mathrm{~h}$. 
(a)

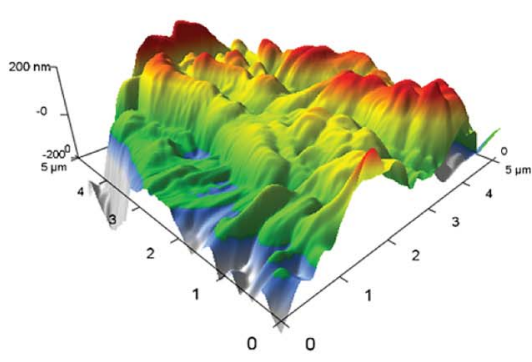

(b)

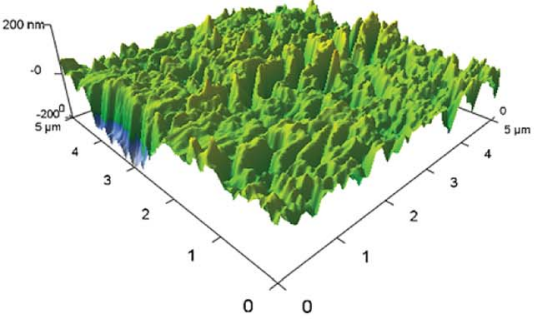

(c)

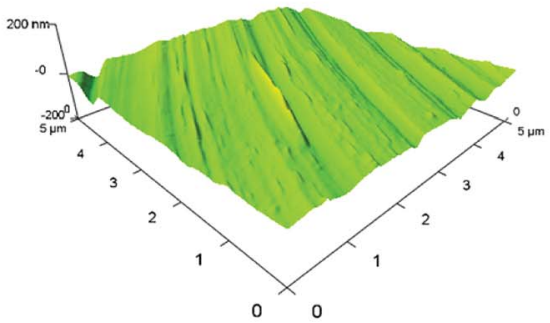

(d)
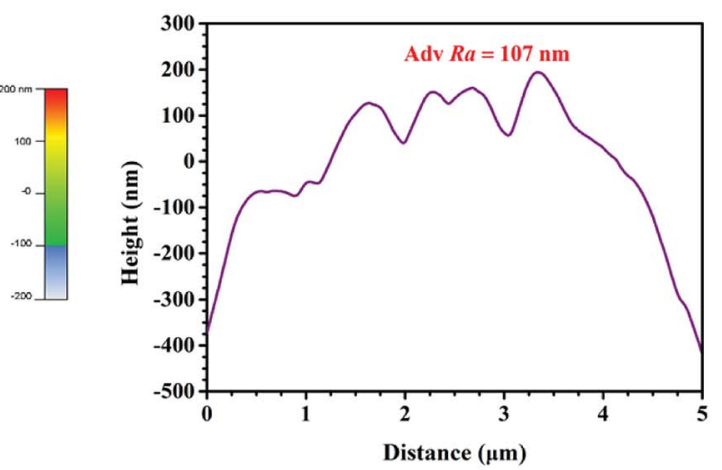

(e)
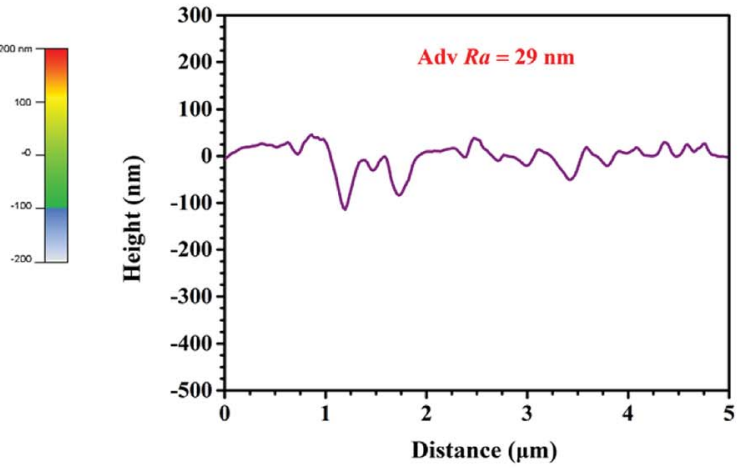

(f)

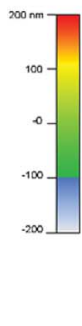

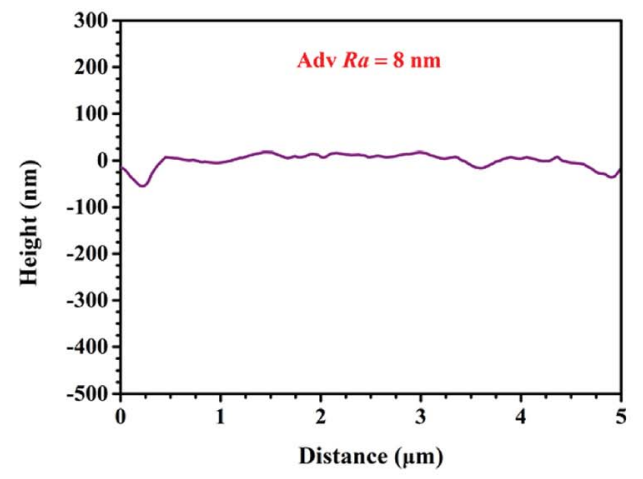

Fig. 10 The images of AFM 3D and height profile plots of corroded steel ( $a$ and d) without HOAT, steel (b and e) with 10 mM HOAT in 1 M H $\mathrm{H}_{2} \mathrm{SO}_{4}$ solution and new polished steel (c and f) for $2 \mathrm{~h}$ at $298 \mathrm{~K}$.

The corrosion holes are large and deep. Fig. 9(b) shows the mild steel soaked into $1 \mathrm{M} \mathrm{H}_{2} \mathrm{SO}_{4}$ solution containing $10 \mathrm{mM}$ HOAT. After soaking for 2 hours, due to the HOAT molecules adsorption on the surface of steel, the steel corrosion is significantly reduced. Fig. 9(c) presents a topography of the polished steel surface. The surface of the steel is very bright and a few polished scratches. Therefore, SEM images can intuitively express the inhibition of HOAT for $t$ steel corrosion in $1 \mathrm{~mol} \mathrm{~L}^{-1} \mathrm{H}_{2} \mathrm{SO}_{4}$.

3.6.2. AFM observation. AFM is used diffusely study the surface nature of materials and roughness of surface. ${ }^{53,54}$ The
3D images of AFM and height profiles of mild steel in $1 \mathrm{~mol} \mathrm{~L}^{-1}$ $\mathrm{H}_{2} \mathrm{SO}_{4}$ without and with $10 \mathrm{mM}$ HOAT for 2 hours at $298 \mathrm{~K}$ are presented in Fig. 10. As showed in Fig. 10(a), 3D topography surface of steel is very rough $1 \mathrm{~mol} \mathrm{~L}^{-1}$ sulfuric acid without HOAT. Fig. 10(b) shows that surface 3D topography of steel is relatively flat with $10 \mathrm{mM}$ HOAT. Fig. 10(c) presents that 3D surface topography of newly polished steel. Fig. 10(d)-(f) are correspond to two-dimensional contour map of blank solution, $10 \mathrm{mM}$ HOAT and new polished, respectively. Moreover, the roughness of the surface after adding the $10 \mathrm{mM}$ HOAT reduce 


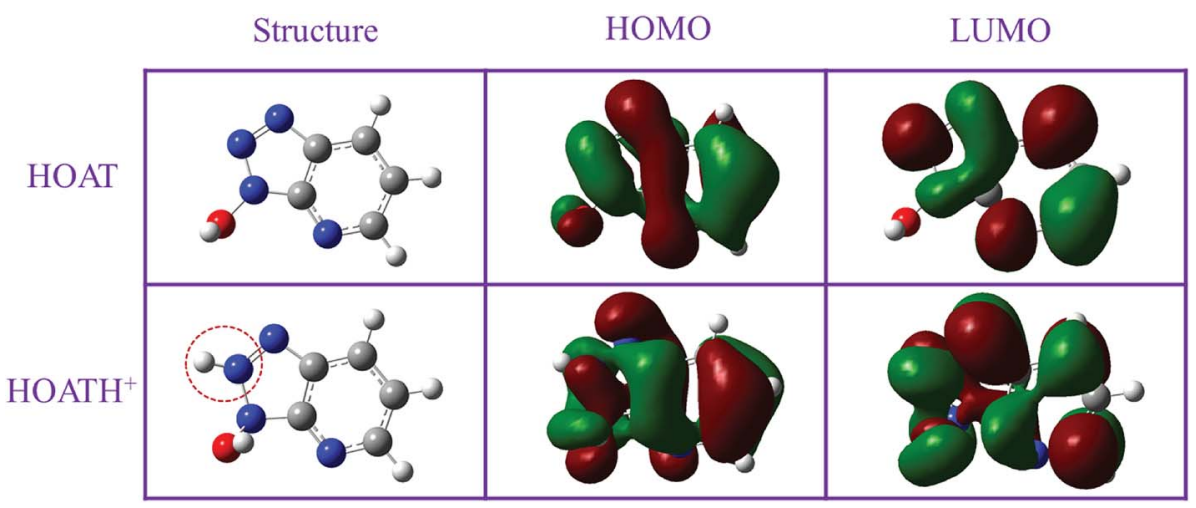

Fig. 11 The optimized structures, HOMO and LUMO of the HOAT and HOATH ${ }^{+}$.

by $29 \mathrm{~nm}$ from the original $107 \mathrm{~nm}$. It shows that HOAT molecules can effectively inhibit steel in sulfuric acid.

\subsection{Quantum chemical research}

To more realistically simulate the state of HOAT molecules in sulfuric acid. Quantum chemical calculation was performed for HOAT and its protonated form in acid. As shown in Fig. 11 and 12 , their structures were optimized, the distribution of electron

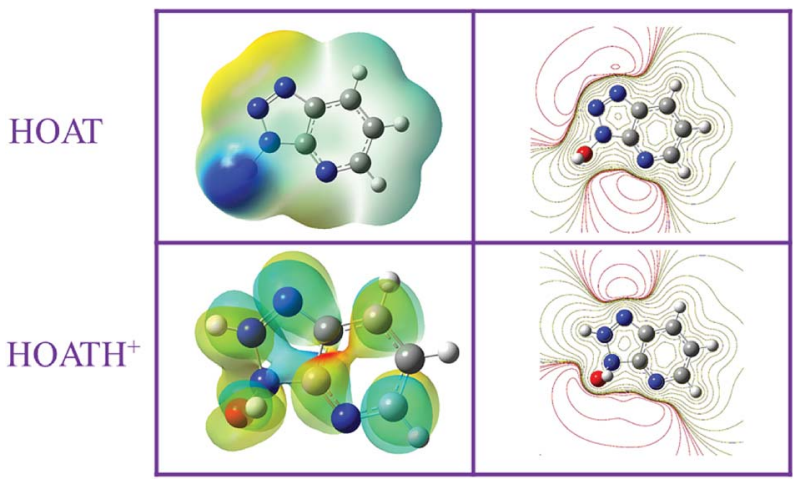

Fig. 12 Surface and contours maps of the electrostatic potential (ESP) of $\mathrm{HOAT}$ and $\mathrm{HOATH}^{+}$. clouds and their energy values, electrostatic potential map, and dipole moments were calculated, respectively. The electron cloud is evenly distributed throughout the HOAT molecule, so the HOAT is most likely to adsorb on the surface of steel in a parallel adsorption manner. In addition, the $\Delta E$ values of HOAT and $\mathrm{HOATH}^{+}$are $5.31 \mathrm{eV}$ and $4.66 \mathrm{eV}$, respectively. It is generally accepted that a small $\Delta E$ value corresponds to a high corrosion inhibition efficiency. ${ }^{30,55}$ The dipole moment values of HOAT and $\mathrm{HOATH}^{+}$are 3.28 Debye and 2.8433 Debye, respectively. Many researchers believe that small value of dipole moment favor the accumulation of corrosion inhibitor molecules on the surface of steel, thereby exhibiting higher corrosion inhibition performance. ${ }^{56}$ Therefore, it can be found that HOAT molecules are protonated to facilitate its adsorption on the steel surface.

Fig. 12 shows the electrostatic potential maps of HOAT and $\mathrm{HOATH}^{+}$, including surface and contours maps, respectively. The blue (positive) and brown-red (negative) regions in the ESP map are related to electrophilic activity and nucleophilicity, respectively. ${ }^{57}$ It is clearly found that the brown-red region is mainly distributed near the nitrogen atom of the HOAT molecule and is conducive to forming a covalent bond with Fe. In addition, the brown-red area of $\mathrm{HOATH}^{+}$is significantly larger than HOAT. Therefore, protonated HOAT is favorably adsorbed on the steel surface.
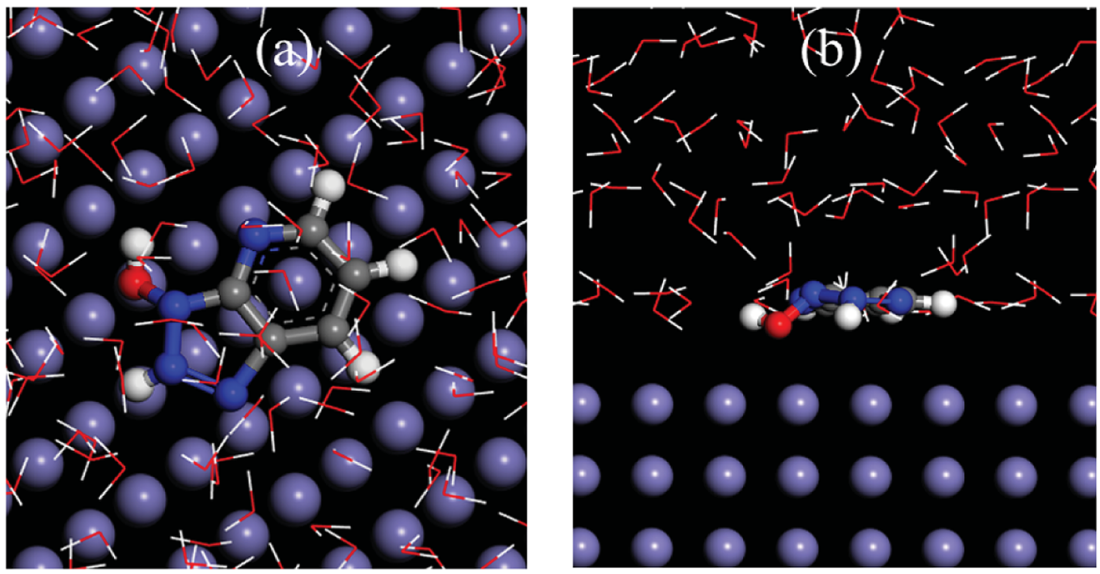

Fig. 13 Equilibrium adsorption configuration for $\mathrm{HOATH}^{+}$on the Fe (110) surface: (a) top and (b) side views. 


\subsection{Molecular dynamics simulation research}

We have in-depth explored the state of HOAT in acid in the previous quantum chemistry calculations. The calculation results show that the HOAT is protonated to facilitate the adsorption on the surface of steel. The top and side views of the $\mathrm{HOATH}^{+}$adsorption on the steel surface are located in Fig. 13. It is obvious that $\mathrm{HOATH}^{+}$is adsorbed on the $\mathrm{Fe}$ (110) surface with nitrogen and oxygen atoms as the reaction sites in parallel, which is consistent with the prediction of the previous frontier molecular orbital. In addition, the binding energy $\left(E_{\text {binding }}\right)$ is calculated using the following formulas (15) and (16): ${ }^{58,59}$

$$
\begin{gathered}
E_{\text {binding }}=-E_{\text {interact }} \\
E_{\text {interact }}=E_{\text {tot }}-\left(E_{\text {subs }}+E_{\text {inh }}\right)
\end{gathered}
$$

where $E_{\text {tot }}$ represents total energy of entire simulation system, $E_{\text {subs }}$ represents the energy except $\mathrm{HOATH}^{+}, E_{\text {inh }}$ represents the energy value of $\mathrm{HOATH}^{+}$. The value of this binding energy is $480.52 \mathrm{~kJ} \mathrm{~mol}^{-1}$ via formulas (15) and (16). This large binding energy value indicates that the HOAT can be closely adsorbed on the steel surface.

\section{Conclusions}

(1) The weight loss tests prove that HOAT is a superior inhibitor at different temperatures for steel in $1 \mathrm{M} \mathrm{H}_{2} \mathrm{SO}_{4}$. Whereas, the inhibition efficiency sharply changes in diverse concentrations of HOAT with increasing temperatures.

(2) The data of Tafel curves show that HOAT is a mixed-type corrosion inhibitor for mild steel in $1 \mathrm{M} \mathrm{H}_{2} \mathrm{SO}_{4}$. Namely, HOAT can both inhibit the cathodic and anodic processes to the mild steel in $1 \mathrm{M} \mathrm{H}_{2} \mathrm{SO}_{4}$.

(3) AFM and SEM images demonstrate a smoother steel surface in $10 \mathrm{mM}$ HOAT than in $1 \mathrm{M}$ sulfuric acid without HOAT, owing to the HOAT compact adsorption on the steel surface.

(4) Computational simulation studies prove that the HOAT adsorbs on surface of mild steel with a parallel mode attribute to HOAT conjugate ring of triazole and azaphenyl ring.

\section{Conflicts of interest}

There are no conflicts to declare.

\section{References}

1 Y. Zhou, L. Guo, S. Zhang, S. Kaya, X. Luo and B. Xiang, RSC Adv., 2017, 7, 23961-23969.

2 M. Ramezanzadeh, Z. Sanaei, G. Bahlakeh and B. Ramezanzadeh, J. Mol. Liq., 2018, 256, 67-83.

3 Y. Qiang, L. Guo, S. Zhang, W. Li, S. Yu and J. Tan, Sci. Rep., 2016, 6, 33305-33319.

4 L. Guo, S. Kaya, I. B. Obot, X. Zheng and Y. Qiang, J. Colloid Interface Sci., 2017, 506, 478-485.

5 A. S. Fouda, M. A. Ismail, A. S. Abousalem and G. Y. Elewady, RSC Adv., 2017, 7, 46414-46430.
6 Y. Meng, W. Ning, B. Xu, W. Yang, K. Zhang, Y. Chen, L. Li, X. Liu, J. Zheng and Y. Zhang, RSC Adv., 2017, 7, 4301443029.

7 A. Mishra, C. Verma, H. Lgaz, V. Srivastava, M. A. Quraishi and E. E. Ebenso, J. Mol. Liq., 2018, 251, 317-332.

8 C. Verma, L. O. Olasunkanmi, E. E. Ebenso and M. A. Quraishi, J. Mol. Liq., 2018, 251, 100-118.

9 E. Alibakhshi, M. Ramezanzadeh, G. Bahlakeh, B. Ramezanzadeh, M. Mahdavian and M. Motamedi, J. Mol. Liq., 2018, 255, 185-198.

10 H. Lgaz, K. Subrahmanya Bhat, R. Salghi, Shubhalaxmi, S. Jodeh, M. Algarra, B. Hammouti, I. H. Ali and A. Essamri, J. Mol. Liq., 2017, 238, 71-83.

11 X. Zheng, S. Zhang, W. Li, L. Yin, J. He and J. Wu, Corros. Sci., 2014, 80, 383-392.

12 G. Khan, W. J. Basirun, S. N. Kazi, P. Ahmed, L. Magaji, S. M. Ahmed, G. M. Khan, M. A. Rehman and A. Badry, J. Colloid Interface Sci., 2017, 502, 134-145.

13 Z. Zhang, N. Tian, X. Li, L. Zhang, L. Wu and Y. Huang, Appl. Surf. Sci., 2015, 357, 845-855.

14 A. Kumar, M. Trivedi, B. Bhaskaran, R. Kishore Sharma and G. Singh, New J. Chem., 2017, 41, 8459-8468.

15 F. El-Taib Heakal, M. A. Deyab, M. M. Osman, M. I. Nessim and A. E. Elkholy, RSC Adv., 2017, 7, 47335-47352.

16 M. M. Solomon and S. A. Umoren, J. Colloid Interface Sci., 2016, 462, 29-41.

17 Y. Qiang, S. Zhang, S. Xu and W. Li, J. Colloid Interface Sci., 2016, 472, 52-59.

18 X. Zheng, S. Zhang, W. Li, M. Gong and L. Yin, Corros. Sci., 2015, 95, 168-179.

19 E. M. Sherif and S.-M. Park, Electrochim. Acta, 2006, 51, 46654673.

20 R. Fuchs-Godec, J. Mol. Liq., 2017, 228, 230-235.

21 Y. Qiang, S. Zhang, L. Guo, X. Zheng, B. Xiang and S. Chen, Corros. Sci., 2017, 119, 68-78.

22 S. Mo, H. Q. Luo and N. B. Li, J. Colloid Interface Sci., 2017, 505, 929-939.

23 K. F. Khaled, J. Appl. Electrochem., 2010, 41, 277-287.

24 H. Huang, Q. Yao, B. Liu, N. Shan and H. Chen, New J. Chem., 2017, 41, 12205-12217.

25 M. A. Deyab, RSC Adv., 2018, 8, 20996-21001.

26 S. Kumar, M. Goyal, H. Vashisht, V. Sharma, I. Bahadur and E. E. Ebenso, $R S C$ Adv., 2017, 7, 31907-31920.

27 Z. Z. Tasic, M. M. Antonijevic, M. B. Petrovic Mihajlovic and M. B. Radovanovic, J. Mol. Liq., 2016, 219, 463-473.

28 K. R. Ansari, M. A. Quraishi and A. Singh, Corros. Sci., 2014, 79, 5-15.

29 K. Stanly Jacob and G. Parameswaran, Corros. Sci., 2010, 52, 224-228.

30 B. Tan, S. Zhang, Y. Qiang, L. Guo, L. Feng, C. Liao, Y. Xu and S. Chen, J. Colloid Interface Sci., 2018, 526, 268-280.

31 M. A. Deyab, M. T. Zaky and M. I. Nessim, J. Mol. Liq., 2017, 229, 396-404.

32 B. Tan, S. Zhang, Y. Qiang, L. Feng, C. Liao, Y. Xu and S. Chen, J. Mol. Liq., 2017, 248, 902-910. 
33 A. Ehsani, M. G. Mahjani, M. Hosseini, R. Safari, R. Moshrefi and H. Mohammad Shiri, J. Colloid Interface Sci., 2017, 490, 444-451.

34 L. Feng, H. Yang, X. Cui, D. Chen and G. Li, $R S C A d v .$, 2018, 8, 6507-6518.

35 N. Labjar, M. Lebrini, F. Bentiss, N.-E. Chihib, S. E. Hajjaji and C. Jama, Mater. Chem. Phys., 2010, 119, 330-336.

36 M. T. Alhaffar, S. A. Umoren, I. B. Obot and S. A. Ali, RSC Adv., 2018, 8, 1764-1777.

37 Y. Qiang, S. Zhang, S. Xu and L. Yin, $R S C A d v ., 2015,5$, 63866-63873.

38 R. K. Gupta, M. Malviya, C. Verma, N. K. Gupta and M. A. Quraishi, RSC Adv., 2017, 7, 39063-39074.

39 B. J. Usman, S. A. Umoren and Z. M. Gasem, J. Mol. Liq., 2017, 237, 146-156.

40 M. A. Azaroual, E. F. El Harrak, R. Touir, A. Rochdi and M. E. Touhami, J. Mol. Liq., 2016, 220, 549-557.

41 L. Liao, S. Mo, H. Luo and N. Li, J. Colloid Interface Sci., 2018, 520, 41-49.

42 N. K. Gupta, C. Verma, R. Salghi, H. Lgaz, A. K. Mukherjee and M. A. Quraishi, New J. Chem., 2017, 41, 13114-13129.

43 L. Liao, S. Mo, J. Lei, H. Luo and N. Li, J. Colloid Interface Sci., 2016, 474, 68-77.

44 Z. Zhang, F. Wang, Y. Liu, S. Wu, W. Li, W. Sun, D. Guo and J. Jiang, RSC Adv., 2018, 8, 20648-20654.

45 A. E.-A. S. Fouda, S. E.-D. H. Etaiw, M. M. El-bendary and M. M. Maher, J. Mol. Liq., 2016, 213, 228-234.
46 J. Haque, V. Srivastava, C. Verma and M. A. Quraishi, J. Mol. Liq., 2017, 225, 848-855.

47 H. S. Gadow, M. M. Motawea and H. M. Elabbasy, RSC Adv., 2017, 7, 29883-29898.

48 Y. Wang, Y. Zuo, X. Zhao and S. Zha, Appl. Surf. Sci., 2016, 379, 98-110.

49 S. Hari Kumar and S. Karthikeyan, Ind. Eng. Chem. Res., 2013, 52, 7457-7469.

50 Sudheer and M. A. Quraishi, Ind. Eng. Chem. Res., 2014, 53, 2851-2859.

51 H. K. Sappani and S. Karthikeyan, Ind. Eng. Chem. Res., 2014, 53, 3415-3425.

52 I. Jevremović, M. Singer, S. Nešić and V. Mišković-Stanković, Corros. Sci., 2013, 77, 265-272.

53 B. Zhang, C. He, X. Chen, Z. Tian and F. Li, Corros. Sci., 2015, 90, 585-596.

54 G. Ji, S. Anjum, S. Sundaram and R. Prakash, Corros. Sci., 2015, 90, 107-117.

55 Y. Qiang, S. Zhang, S. Yan, X. Zou and S. Chen, Corros. Sci., 2017, 126, 295-304.

56 L. Guo, S. Zhu, S. Zhang, Q. He and W. Li, Corros. Sci., 2014, 87, 366-375.

57 Y. Qiang, S. Zhang, B. Tan and S. Chen, Corros. Sci., 2018, 133, 6-16.

58 Y. Yu, D. Yang, D. Zhang, Y. Wang and L. Gao, Appl. Surf. Sci., 2017, 392, 768-776.

59 M. A. Deyab, M. M. Osman, A. E. Elkholy and F. El-Taib Heakal, RSC Adv., 2017, 7, 45241-45251. 